\title{
Da Origem de Alguns Fenômenos Lingïísticos Peculiares ao Falar Rural
}

Joyce Elaine de ALMEIDA

Universidade Estadual de Londrina

Resumo: Esta pesquisa pretende investigar a origem de algumas marcas características do falar rural a partir dos pressupostos teóricos da Sociolingüística e da análise de entrevistas com informantes rurais. Tal estudo resulta da percepção da característica conservadora de tal falar, revelando traços que reconstituem a formação da língua portuguesa no Brasil. Espera-se que os resultados deste estudo possam auxiliar demais pesquisadores que se ocupam com a língua e sua relação com a sociedade.

Palavras-chave: falar rural; variação lingüística; origem lingüística.

Abstract: This research intends to investigate the origin of some characteristic features of rural dialect based on Sociolinguistics presuppositions and on the analyses of interviews with rural informants. This study results from the perception of the conservative feature of this dialect, revealing traces which reconstitute the formation of the Portuguese language in Brazil. We hope that the results from this research can help another researchers who study languages and societies.

Keywords: rural dialect; language variation; linguistic origin.

Resumen: Este estudio pretende investigar el origen de algunas marcas características del modo de hablar rural a partir de los presupuestos teóricos de la Sociolingüística y del análisis de entrevistas con informantes rurales. Tal investigación deviene de la percepción de la característica conservadora de tal manera de hablar, revelando rasgos que reconstituyen la formación de la lengua portuguesa en Brasil. Se espera que los resultados de este estudio puedan auxiliar a los demás investigadores que se ocupan de la lengua y de la sociedad.

Palabras-clave: hablar rural; variación lingüística; origen lingüística. 


\section{Introdução}

O falar rural apresenta algumas marcas que evidenciam sua relação com o passado, pois traz, em suas formas diversas, alguns traços da língua portuguesa em sua formação, os quais revelam resquícios de outras línguas, como latim, línguas africanas e línguas indígenas. Este trabalho pretende, pois, apresentar as possíveis origens de alguns traços característicos deste falar a partir dos pressupostos teóricos da Sociolingüística.

A seguir, apresentam-se algumas marcas peculiares do falar rural e o posicionamento de pesquisadores acerca de suas possíveis origens. Cabe ressaltar que os exemplos apresentados para cada item foram extraídos de um corpus constituído de entrevistas realizadas em 2002, na zona rural de Paiquerê, distrito de Londrina, com a finalidade de compor a tese de doutorado da autora deste artigo.

\section{Aspectos Fonéticos}

\subsection{Monotongação}

\section{Monotongação de ei para e \\ Ex: di primeru}

Monotongação de ou para o

Ex: otru

Monotongação de ai para a:

Ex: baxu

Melo (1981, p. 79), ao abordar tal processo, recusa a possibilidade de ele se dar por influência africana, conforme aponta Mendonça (1935, p. 118). Para Melo (1981), tal fato resulta de influência latina. Paiva (1998a) segue a mesma idéia de Melo, afirmando que a tendência de evitar os ditongos é "atestada no português ao longo de toda a sua história” (PAIVA, 1998a, p. 219), pois, no latim vulgar, já se evidenciava tal tendência.

Antes desses autores, Boléo (1943) já afirmava:

A redução dos ditongos ei a ê e ou a ô- bêjo, pêxe, ôro, 'dêxa de brincadêra’ - não é facto lingüístico próprio do Brasil: encontra- 
se em várias regiões de Portugal, e com bastante freqüência. $\mathrm{Na}$ Beira Baixa, província que conheço melhor, é êle correntíssimo. (BOLÉO, 1943, p. 24)

Reforçando as idéias citadas, Delgado (1951) apresenta em seu estudo casos de monotongação ocorridos em Portugal como, por exemplo, "otro" e "roxinol".

Também Cintra (1970) aponta a possibilidade da origem européia para tal fenômeno. $\mathrm{O}$ autor verificou a distribuição dos ditongos oi e ei e suas variantes em Portugal e constatou que, em determinadas regiões, se conservam os ditongos em sua forma original, noutras regiões os ditongos se alteram e há, também, a ocorrência da monotongação em algumas localidades.

\subsection{Iotização}

\section{Ex: - muié}

Nascentes (1953, p. 49) comenta as razões de ordem etnográfica que resultaram na dificuldade da pronúncia do lh pela classe inculta: "A dita classe era composta em sua maioria de índios e africanos que não possuíam este fonema em suas línguas; tiveram de aprendê-lo, aprenderam estropiadamente e deste modo o transmitiram aos seus descendentes."

Mendonça (1935, p. 112) afirma ocorrer esse processo devido a uma influência africana. Já para Melo (1981), essa transformação pode ser uma influência românica ou africana. Apesar de apontar as duas hipóteses, o autor dá preferência à segunda:

Sem embargo, porém de ser evolução românica a $\mathrm{lh} / \mathrm{y}$, sou inclinado a explicá-la, aqui no Brasil, por influência africana, uma vez que o fato ocorre de regra nas zonas mais africanizadas, sendo quase geral num ponto intensamente trabalhado dos negros, São João da Chapada, em Minas, segundo nos informa Aires da Mata Machado. (MELO, 1981, p. 81)

A despeito da hipótese da origem africana, vale lembrar as considerações apontadas por Boléo (1943), em que o autor afirma 
que no distrito de Ponta Delgado, designadamente na povoação de Arrifes, ainda se usava esta pronúncia: "orvaio, carríe (carrilho, nome do carolo = interior da maçaroca, depois de tirados os grãos), ovêias, coêio, cestías (cestilhas, intrumentos para caçar pássaros), abêia, borraio, joeieira, ajoeiar (ajoelhar)" (BOLÉO, 1943, p. 47).

Aguilera (1999) trata desse processo, apresentando o parecer de pesquisadores, como Nascentes (1953), Penha (1972), Câmara Júnior (1979; 1981), Elia (1979), Jota (1981) e Melo (1981) e constata não haver consenso quanto à nomeação do processo, pois, enquanto alguns autores o consideram uma despalatalização, outros o conceituam como uma iotização. Para Aguilera, o que ocorre é uma iotização ou uma semivocalização (e não uma vocalização, pois o yode é uma semivogal), descartando a possibilidade de uma despalatalização, pois o yode é palatal também. No decorrer de seu estudo, a autora afirma que esse processo é "um traço predominante na fala rural ou inculta que se expande por todas as regiões brasileiras como se pode documentar pelos Atlas já publicados" (AGUILERA, 1999, p. 158).

\subsection{Alçamento da pretônica}

\section{Ex: nutícia}

É interessante ressaltar que essa alteração ocorre em outras variedades do português brasileiro e do português europeu, independentemente de se tratar de variedade urbana ou rural.

\subsection{Rotacismo: alteração de 1 para $r$ em trava silábica}

Ex: vortei

Boléo (1943) comenta a ocorrência deste processo também em Portugal:

No que diz respeito às consoantes $\mathrm{r}$ e 1 , devo recordar que a substituição da segunda pela primeira (marvado, minh'arma) não se encontra só no português popular do Brasil. Depara-se igualmente no português popular de algumas regiões portuguesas. (BOLÉO, 1943, p. 25) 


\subsection{Alteração da desinência ram para ru e rum}

\section{Ex: aprenderu}

Para Melo (1981, p. 82-83), tal ocorrência se dá por influência latina. Para explicar tal fato, o autor adota a evolução latina: -unt/ -om/ -o: -amarunt/ -amarom/- amaro.

\subsection{Alteração de $v$ para $b$}

Ex: braba

Coutinho (1958, p. 119), ao se referir às mudanças do fonema /b/ do latim ao português, afirma: "modifica-se às vezes em v, outras cai". Exemplos citados pelo autor são: caballu/cavalo, nebula/ névoa, em que ocorre a alteração de $\mathbf{b}$ para $\mathbf{v}$ e $i b a m / i a$, em que ocorre a queda do $\mathbf{b}$.

Cabe ressaltar que a forma arcaica da variante em questão é bárbaro, portanto, as formas apresentadas conservam marcas lingüísticas da origem do vocábulo.

Em variedades do norte de Portugal, também ocorre esta variação, onde conservaram mais fortemente traços do português antigo.

\subsection{Apócope do $r$}

\section{Ex: muié}

Melo (1981, p. 81) entende que tal ensurdecimento seja uma influência latina, recusando a tese de Mendonça (1935, p. 115) de que haja aí uma influência africana. A supressão de segmentos em fim de palavra é um processo que caracteriza o latim vulgar e que se manteve presente e atuante na história das línguas latinas.

Boléo (1943) afirma que, em Portugal, “a supressão do r em frases é ainda mais freqüente nos falares populares." Com isso, a origem européia é a mais provável. 


\subsection{Síncope}

Ex: memu

Coutinho (1958, p. 158) aponta exemplos de síncope ocorridos na evolução do latim para o português, como: "malu/mau, mediu/meio, rivo/rio, lepore/lebre, veritate/verdade, opera/obra, liberare/livrar", por exemplo.

Nascentes (1953, p. 64), em seu estudo sobre a linguagem carioca, aborda tal caso, afirmando: "A síncope das postônicas que se deu na passagem do latim para o português, continua atuando na classe inculta com grandes alterações na estrutura da palavra."

\subsection{Aférese}

\section{Ex: sistindu}

Mendonça (1935, p. 115) atribui a origem africana para este processo.

Apesar disto, à aférese também se atribui a origem latina. Williams (1975, p. 111) afirma que "a perda da vogal inicial de uma palavra é fenômeno muito comum, mas que não ocorreu com nenhuma regularidade."

\subsection{Metátese}

$$
\text { Ex: - drobanu }
$$

Mendonça (1935, p. 116) atribui origem africana a este processo.

Este processo é citado por Williams (1975, p. 119) como uma das evoluções da língua latina para o português e cita, como exemplos, as formas geolho/joelho, sibilare/silvar, fenestram/feestra/ fresta, entre outras. Com isto, pode-se refutar a hipótese de Mendonça (1935). 


\subsection{Assimilação}

\section{Ex: aparecenu}

Para Melo (1981, p. 83), tal processo é resultado de influência latina, combatendo teses de que haja aí influência tupi ou africana.

Coutinho (1958, p. 254) aponta vários casos de assimilação na evolução do latim para o português, como: persona/pessoa, nova(c)ula/navalha, persicu/pessicu/pêssego.

Williams (1975, p. 113) afirma que os processos da assimilação e o da dissimilação ocorreram na evolução do latim para o português, entre vogais e entre consoantes, exemplificando a partir das seguintes formas: persicum/pêssego.

\subsection{Prótese}

\section{Ex: alembrá}

Coutinho (1958, p. 157) aponta casos de prótese na evolução do latim para o português, como por exemplo: stare/estar, scribere/escrever; portanto pode-se refutar as idéias de Amaral (1920), pois não se trata de um fenômeno típico do falar rural. Apesar disso, a variante alembrá é uma forma do falar rural.

É interessante apontar, aqui, exemplos que continuam ocorrendo no português, como: scan/scanear/ escanear.

\section{Aspectos Lexicais}

Ex: pra mó di dexá limpo

O uso da expressão pra mó di é assim explicado por Amaral (1920): "o nosso caipira usa a fórmula por amor de para exprimir circunstância de causa" (AMARAL, 1920, p. 81). Conforme aponta o estudioso, tal expressão é usada de forma diferenciada, como: pramor de, mor de, mó de.

Segundo Nascentes (1953, p. 111), "a locução por amor de aparece tão desfigurada que quase fica irreconhecível: prumode." 
Segundo o autor, ocorrem, em Portugal, as seguintes formas: Por'môr de (VASCONCELOS, Filologia mirandesa, II, 157 apud NASCENTES, 1953), pr'amor de (VASCONCELOS, Opusculos, II, 507 apud NASCENTES, 1953).

Verdelho (1982, p. 122-123) aponta exemplos da ocorrência do termo "pro môr de" e "p'ra môr de" em textos do romance regionalista português.

\section{Aspectos Sintáticos}

\subsection{Ausência de concordância nominal}

Ex: us homi quase nenbum vai

A tendência de, no falar rural, marcar o plural apenas no determinante é apontada por Melo (1981) como uma influência africana:

[...] tenho que a influência mais profunda das línguas africanas no português brasileiro se fez sentir na morfologia. É a simplificação e redução das flexões. Realmente, em nossas linguagens populares rareiam as desinências de plural, que tendem a se restringir ao primeiro determinante da frase. E isso tão mais amplamente quando mais baixa a camada popular. (MELO, 1981, p. 78)

Entretanto, essa idéia já é rebatida por Boléo (1943), que afirma ocorrer tal fenômeno também em Portugal, embora esporadicamente.

Ao encontro das idéias de Boléo, Naro e Scherre (1993) apontam a origem européia para tal caso. Cabe ressaltar que, no português europeu falado, tal forma também está presente nos dias atuais.

\subsection{Ausência de concordância verbal}

Ex: nóis veiu juntu 
A simplificação das flexões verbais é apontada por Melo (1981, p. 78) como uma influência africana. O autor, abordando a tendência à simplificação, afirma:

O verbo também sofre bastante as conseqüências dessa atitude simplista. Muita vez só há oposição de desinência entre a primeira e as demais pessoas, como se vê, por exemplo, do indicativo presente do verbo comprar: eu compro, tu compra (a $2^{a}$ pessoa de regra só ocorre na linguagem insultuosa), ele compra, nóis compra, eis compra (MELO, 1981, p. 78).

Para Mello (2002, p. 355), as não concordâncias nominal e verbal seriam resultado do contato lingüístico do Português com outras línguas durante o processo de colonização do Brasil, originando, desta forma o que a autora classifica com PNP (português não-padrão).

Naro e Scherre (1993) abordam o português popular do Brasil, apontando várias fontes para sua origem. Os autores afirmam: "Vemos a atração de forças de diversas origens - algumas oriundas da Europa, outras da América, outras, ainda, da África - que juntas se reforçaram para produzir o português popular do Brasil" (NARO; SCHERRE, 1993, p. 437).

Em seu estudo, os autores tratam da variabilidade da concordância nominal e verbal, apontam estudos que defendem a idéia da influência africana para tal variabilidade, tais como Melo (1981) e Mello (2002), mas discordam dessa idéia, apontando a influência européia para tal fenômeno.

Conforme os autores, a variação na concordância verbal tem um componente que parece puramente fonológico. É o caso da redução de casos como: comem/come, em que ocorre a desnasalização. Já os casos de redução morfológica, como, por exemplo, comeram/ comeru, teriam ocorrido posteriormente e por analogia à redução fonológica.

A redução fonológica é comum na fala popular de Portugal, portanto, Naro e Scherre (1993) atribuem a origem européia para as não concordâncias verbal e nominal.

Cabe ressaltar que, além da concordância verbal e nominal, os autores apontam todos os casos de desnasalização - como no caso de homem/home - à origem européia. 


\section{Considerações Finais}

Com base nesses dados, constata-se o caráter conservador do falar rural, pelo fato de condensar resquícios de outras línguas.

Pode-se, então, afirmar que este falar constitui fonte de riqueza cultural, pois, a partir de seus traços, pode-se reconstruir parte da formação da língua portuguesa no Brasil, analisando as marcas que denunciam o possível contato entre europeus, povos africanos e indígenas.

\section{Referências Bibliográficas}

AGUILERA, Vanderci de Andrade. Um estudo geolingüístico da iotização no português brasileiro. In: . (Org.) Português no

Brasil: estudos fonéticos e fonológicos. Londrina: Eduel, 1999. p. 155180.

AMARAL, Amadeu. O dialeto caipira. São Paulo: Anhembi, 1920.

BOLÉO, Manuel de Paiva. Brasileirismos: problemas de método. Coimbra: Coimbra, 1943.

CINTRA, L. F. Lindley. Os ditongos decrescentes ou e ei: um esquema de um estudo sincrônico e diacrônico. In: SIMPÓSIO DE FILOLOGIA ROMÂNICA, 1., 22 a 28 de agosto de 1958, Faculdade Nacional de Filosofia da Universidade do Brasil. Anais... Rio de Janeiro: MEC, 1970.

COUTINHO, Ismael de Lima. Pontos de Gramática Histórica. Rio de Janeiro: Livraria Acadêmica, 1958.

DELGADO, Manuel Joaquim. A linguagem popular do Baixo Alentejo. [S.1.]: [s. n.], 1951.

MELO, Gladstone Chaves de. A língua do Brasil. 4. ed. Rio de Janeiro: Padrão, 1981. 
MELLO, Heliana Ribeiro. Português padrão, português não padrão e a hipótese do contato lingüístico. In: ALKMIN, Tânia Maria (Org.). Para a história do português brasileiro. São Paulo: Humanitas/ FFLCH/USP, 2002.

MENDONÇA, Renato. A origem africana no português do Brasil. 2. ed. São Paulo: Companhia Editorial Nacional, 1935.

NARO, Anthony Julius; SCHERRE, Maria Marta Pereira. Sobre as origens do português popular do Brasil. Delta, v. 9, p. 437-454, 1993. (Número Especial)

NASCENTES, Antenor. O linguajar carioca. 2. ed. Rio de Janeiro: Organização Simões, 1953.

VERDELHO, Evelina. Linguagem regional e linguagem popular no romance regionalista português. Lisboa: Instituto Nacional de Investigação Científica, 1982.

WILLIAMS, Edwin B. Do latim ao português: fonologia e morfologia históricas da língua portuguesa. 3. ed. Rio de Janeiro: Tempo Brasileiro, 1975. 